\title{
Assessment of Knowledge, Attitude and Associated Factors toward COVID-19 among Nurses Who Work in South Gondar Zone, Hospitals, Northwest Ethiopia 2020, Institution-based cross-sectional Study
}

Dejen Getaneh Feleke ( $\square$ dejengetaneh38@gmail.com )

Debre Tabor University

Sheganew Fetene Tassew

Debre Tabor University

Ermiase Sisay Chanie

Debre Tabor University

Research

Keywords: Knowledge, Attitude, Coronovirus-2019, Nurse, Ethiopia

Posted Date: September 1st, 2020

DOI: https://doi.org/10.21203/rs.3.rs-68848/v1

License: (c) (1) This work is licensed under a Creative Commons Attribution 4.0 International License.

Read Full License 
Assessment of Knowledge, Attitude and Associated Factors toward COVID-19 among Nurses Who Work in South Gondar Zone, Hospitals, Northwest Ethiopia 2020, Institution-based crosssectional Study.

Dejen Getaneh Feleke ${ }^{1} *$ (dejengetaneh38@gmail.com), Sheganew Fetene Tassew ( $\underline{\text { sheganewabeba@gmail.com), }{ }^{1} \text { Ermiase Sisay Chanie (ermisis1888@gmail.com) }}$

Authors' affiliation:

${ }^{1}$ Department of Nursing, College of Health Sciences, Debre Tabor University, P.O.BOX 272, Debre Tabor, Ethiopia.

*Corresponding author: Lecturer of Pediatrics and Child Health Nursing @ Debre Tabor University, email: dejengetaneh38@gmail.com: P.O.Box:272, Debre Tabor University Debre Tabor, Ethiopia. 


\section{ABSTRUCT}

Background: - Coronavirus disease 2019 is an emerging respiratory disease that is caused by a novel coronavirus and was first detected in December 2019 in Wuhan, China. The world is affected by the Corona Virus Disease in 2019. In sub-Saharan Africa Including Ethiopia there is no study conducted on level of Knowledge, Attitude and Associated Factors toward Coronavirus disease in 2019 among Health care workers Specifically Nurses.

Objective: - This study aims to assess the level of Knowledge, Attitude and Associated Factors toward Coronavirus disease in 2019 among Nurses Who Work in South Gondar Zone, Hospitals, Northwest Ethiopia, 2020.

Methods: - An Institution-based cross-sectional study was conducted among 166 Nurses in South Gondar Zone, Ethiopia, From June $1^{\text {st }}-30 / 2020$. To select study participants after proportional allocation of study subjects to each Hospital, simple random sampling technique were to be used. The Data was entered into Epi info version 7.2.0.1, and exported to Statistical Package for Social Sciences window version 24 for analysis. Binary and Multivariable logistic regression wasl used to see the association between dependent and independent variables. Adjusted odds ratio with 95\% confidence interval was computed. P-value $<0.05$ was used to declare association. Finally; the result is presented in the form of texts, tables, and graphs.

Results: - Of 166 Nurses, 166 (100\% response rate) responded to the online interview questionnaire. From 166 nurses, $57.2 \%$ of the participants were Females and $42.8 \%$ were males, $41.6 \%$ of the respondents were between the ages of 20 and 29 years. About $84.9 \%$ had good knowledge and $63.3 \%$ favorable attitude of COVID-19. Wearing general medical masks can prevent one from acquiring infection by the co vid-19 virus $(\mathrm{AOR}=0.44,95 \% \mathrm{CI}=0.005-0.362$ were factors of knowledge about COVID-19. Whereas, strongly agree Medical staffs are ready to participate in antiepidemic in the community $(\mathrm{AOR}=0.08,95 \% \mathrm{CI}=(0.003-1.76$

Were factors of attitude about COVID-19.

Conclusion: In this study, most of the nurses had good knowledge and favorable attitude regarding COVID-19. Wearing general medical masks can prevent one from acquiring infection by the covid-19 virus were the factors in association with knowledge OF nurses on COVID-19. Similarly, Medical staffs are ready to participate in antiepidemic in the community factors association with attitudes of nurses on COVID-19.

Keywords: - Knowledge, Attitude, Coronovirus-2019, Nurse, Ethiopia 


\section{Background}

Coronavirus disease 2019 (COVID-19) is an emerging respiratory disease that is caused by a novel coronavirus and was first detected in December 2019 in Wuhan, China. The disease is highly infectious, and its main clinical symptoms include fever, dry cough, fatigue, shortness of breath, sore throat, myalgia, and dyspnea (1-3). The novel coronavirus is very similar in symptomatology to other viral respiratory infections. Cases vary from mild forms to severe ones that can lead to serious medical conditions or even death. Right now, it is believed that symptoms may appear in 2 to 14 days, as the incubation period (IP) for the novel COVID-19 has not yet been confirmed. There has been speculation about the virus spreading while the carrier (infected person) is not showing any symptoms, but that has not been confirmed as a scientific fact $(1,4)$. The novel COVID-19 was first reported in December 2019, as a cluster of acute respiratory illness in Wuhan, Hubei Province, China, from where it spread rapidly to over 198 countries. It was declared as a global pandemic by WHO on 12th March 2020 (5, 6). COVID-19 is a new disease that is a large family of viruses that are common in people and many different species of animals, including camels, cattle, cats, and bats. Rarely, animal COVID-19 can infect

people and then spread between people, and now with this new virus. Although COVID-19 and influenza infections may present with similar symptoms, the virus responsible for COVID-19 is different with respect to community spread and severity (7). Nowadays, COVID-19 is a lifethreatening agent with the worldwide spread and it has become an international concern. Health workers, especially nurses, have close contact with infected patients and have a decisive role in infection control (8). The newest member of the COVID-19 family has been recently identified that results in acute and severe respiratory syndrome in humans (9). The first infected patient who had clinical manifestations such as fever, cough, and dyspnea was reported on 12 December 2019 in Wuhan, China $(9,10)$. Since then, COVID-19 has spread rapidly to other countries via different ways such as airline traveling, and now, COVID-19 is the world's pandemic problem (11). Low pathogenicity and high transmissibility are the two unique features of this new virus that distinguish it from other members of the COVID-19 family; this subsequently makes it difficult to control so that after passing more than three months of identifying the first infected human, the rate of infection and mortality is still high and COVID-19 has become a great public health concern in the world. No antiviral agents have been recommended so far and prevention is 
the best way to limit the infection $(12,13)$. It seems that the current widespread outbreak has been partly associated with a delay in diagnosis and poor infection control procedures (14). As of $22^{\text {th }}$ of August 2020, over 23,266,1431 cases of COVID-19 have been reported with a death toll of over 805,863 patients and 15,817,397 cases are recovered in the world (15). In Studies conducted in different countries such as, in Iran, More than half of the nurses 56.5\% had good knowledge of COVID-19 (16), and in Another Study done in Iran, the overall achieved knowledge score regarding COVID-19 characteristics was $90 \%$ with $60.8 \%$ of the general population having moderate knowledge towards the disease (17). Study Conducted in Pakistan, HCWs have good knowledge of $93.2 \%$, positive attitude $(8.43 \pm 1.78)$ regarding to COVID-19 (18). In Study done in Wuhan, Hubei province, China, the overall correct rate of the knowledge questionnaire was 90\% (19). Study done at Makerere University Teaching Hospitals, Uganda, Overall, 69\% had sufficient knowledge, 21\% had positive attitude toward COVID-19 (20). Study Conducted at District 2 Hospital, Ho Chi Minh City, a mean score of knowledge and attitude of $8.17 \pm 1.3$ (range 4-10) and $1.86 \pm 0.43$ (range 1-5), respectively (21).

The outbreak of COVID-19 officially confirmed to be in Ethiopia on March 13, 2020 (22-24). In Ethiopia updated August 22 2 th 2020, 39,033 Confirmed cases reported, among this 14,480 patients are recovered and 662 deaths are occurred (23).

Knowledge and Attitude toward COVID-19 can be affected by a multitude and interrelated factors: Among which socio-demographic and economic characteristics related factors, Work place related factors, Nurses Knowledge, and Attitude about COVID-19 related factors.

HCWs are at the frontline of COVID-19 pandemic response and are exposed to dangers like pathogen exposure, long working hours, psychological distress, fatigue, occupational burnout and stigma, and physical violence (25). A poor understanding of the disease among HCWs can result in delayed identification and treatment leading to rapid spread of infections. Over 100 health workers have lost their lives to COVID-19, a tragedy to the world and a barrier to fight against the disease (26). Guidelines for HCWs and online refresher courses have been developed by WHO, CDC, and various governmental organizations in various countries to boost the knowledge and prevention strategies (27).

The battle against COVID-19 is still continuing in Ethiopia. To guarantee the final success, people's adherence to these control measures is essential, which is largely affected by their knowledge, attitudes towards COVID-19 in accordance with KA theory $(28,29)$. To facilitate 
outbreak management of COVID-19 in Ethiopia, there is an urgent need to understand the public's awareness of COVID-19 at this critical moment.

As transmission within hospitals and protection of HCWs are important steps in the epidemic, the understanding of having enough information regarding sources, clinical manifestations, transmission routes, and prevention ways among HCWs can play roles for this gal assessment. Since nurses are in close contact with infected people, they are the main part of the infection transmission chain and their knowledge of COVID-19 prevention and protection procedures can help prevent the transmission chain. There is paucity of literature on KA of HCWs toward the COVID-19 pandemic. To our knowledge, no study has been done in sub-Saharan Africa including Ethiopia to assess KA toward COVID-19 specifically among HCWs and especially nurses to play critical roles in the prevention of COVID-19. Ethiopia is one of the most epidemic countries for COVID-19 and there is no information regarding the awareness and attitude of Ethiopian nurses about this infectious disease. Therefore, this study will aim to assess Knowledge, Attitude and Associated Factors toward COVID-19 among Nurses Who Work in South Gondar Zone, Hospitals, and Northwest Ethiopia, 2020. 


\section{METHODS AND MATERIALS}

\section{Study Area and Period}

The study was being conducted in South Gondar Zone. South Gondar Zone is one of the 11 Zones of the Amhara National Regional State and has a total of 18 Woredas. Based on the information from South Gondar Zone Administrative Health Bureau, the total population in South Gondar Zone is 2,609,823, among whom are a $49.9 \%$ male, and $50.1 \%$ are females. The Weather condition of south Gondar zone is $4 \%$ kola, $78.5 \%$ woynadega, $17 \%$ dega, and $0.5 \%$ wurch. The health service delivering institutions are comprised of one general governmental hospital and seven governmental District Hospitals during data collection. Currently During the data collection period, there are three hundreds (300) Nurses in South Gondar Zone among whom one hundreds, thirty- six (136) Nurses in Debre Tabor General Hospital, thirty- seven (37) Nurses in Adiss zemen Hospital, Seventeen (17) Nurses in Ebenate Hospital, twenty three (23) Nurses in Nifasmewucha Hospital, Twenty Five (25) Nurses in Tachgayint Hospital, twenty two (22) Nurses in Mekane-Eyesus Hospital, Seventeen (17) Nurses in Andabet Hospital, twenty three (23) Nurses in Simada Hospital (30). The study was conducted from June $1^{\text {st }}-30 / 2020$.

\section{Study design and participants characteristics}

Institutional-based cross-sectional quantitative study was conducted. All Nurses working in South Gondar Zone Hospitals were the source population of the study and Study populations were select Nurses working in South Gondar Zone Hospitals were the source population of the study. Nurses working in South Gondar Zone Hospitals and available during the data collection period were included in the study, and Nurses who are on Annual leave and sick during data collection were excluded from the study.

\section{Sample size determination and Sampling procedure}

The sample size is determined using a single population proportion formula using the proportion of Health workers Level of knowledge (89\%) in a study conducted in China (31) with $95 \%$ confidence interval and precision level of $5 \%$.

$$
\mathrm{ni}=\frac{(\mathrm{Z} \alpha / 2) 2 \mathrm{p}(1-\mathrm{P})}{\mathrm{d}^{2}}=\frac{(1.96) 2 * 0.89(1-0.89)}{0.05^{2}}=151
$$

Where $\mathrm{n}=$ Sample size needed

$$
\mathrm{z}=\text { Standard normal variable at 95\% confidence level (1.96) }
$$


$\mathrm{p}=$ the Level of Nurses Knowledge in Iran (0.89)

$\mathrm{d}=$ Margin of error $(0.05)$

$\mathrm{Z} \alpha / 2=$ Value of standard normal distribution corresponding to significant level of alpha

(a) 0.05 which is 1.96 . Then add $10 \%$ ( contingency) $=166$

An overall sample size of 166 Nurses was required for the study.

To select study participants after proportional allocation of study subjects to each Hospital, simple random sampling techniques were to be used (Figure 1).

\section{Study variables}

\section{Dependent variables}

Knowledge and Attitude toward COVID-19.

\section{Independent variables}

\section{Socio-Demographic and Economic Characteristics Related Variables:-}

Age of participants, Sex of participants, marital status, Educational status, monthly income, working institution name

Workplace related Variables:-

Work experience in clinical area, Nurses work per day, Overworked status of nurses, Source of information on COVID-19

\section{Knowledge of Nurses about COVID-19 related Variables:-}

Clinical Manifestation of Covid-19, source of infection, of Covid-19, prevention methods of COVID-19, IP for COVID-19, transmission route of COVID-19 susceptible to COVID-19, available of COVID-19 vaccine, COVID-19 Antibiotics, isolation period of COVID-19, medical masks of COVID-19, pathogenesis of COVID-19.

\section{Attitude of Nurses about COVID-19 related Factors:-}

Black race toward COVID-19, Wearing material of COVID-19, Hand wash related to COVID19. Clinical Manifestation of COVID-19, management of COVID-19, Condition of COVID-19, Controlled of COVID-19, Isolation of COVID-19, Medical staffs participate to COVID-19, family members may get an infection by COVID- 19 .

\section{Operational Definition}

Attitude: - Participants with score of greater than or equal to 6 attitude questionnaire answered were consider having favorable attitude and those who scored less than 6 attitude questionnaire answered were considered having un-favorable attitude toward COVID-19 (8). 
Knowledge: - Appropriate responses from nurses about COVID-19 through the structured knowledge questionnaires answered by $>=8$ correct response from 13 knowledge questions) were considered having good knowledge and those below $<8$ correct response from 13 knowledge questions) were considered having poor knowledge (8).

Suspected case of COVID-19:- is a person presenting with fever $\left(>38^{\circ} \mathrm{C}\right)$ or history of fever and symptoms of respiratory tract illness, e.g., cough, difficulty in breathing, AND a history of travel to or residence in a country/area or territory reporting local transmission of COVID-19 disease during the 14 days prior to symptom onset (1)..

Probable case: - is a suspect case for which testing for COVID-19 is inconclusive (1).. Confirmed case:- is a person with laboratory confirmation of COVID-19 infection, irrespective of clinical signs and symptoms (1).

\section{Data collection tools and techniques:-}

\section{Data collection tools}

The Data was collected using a pretested and structured Self-administered questionnaire, which was adapted from WHO COVID-19 guidelines, Training manuals and published articles with some modifications to the local context $(16-21,31)$ ). The questionnaire was prepared in the English version. The questionnaires addressing provider and institutional characteristics of Nurses; structured questions addressing knowledge of Nurses towards COVID-19 and Likert Scale guide addressing the Attitude of nurses towards COVID-19. (for Detail sees Annexes-11.3) Data collection techniques

A total of seven trained data collectors and three supervisors (who have an experience of data collection done as task force of COVID-19 and Quorante Treatment Center of COVID-19) were select. Two days of training was given for data collectors and supervisors regarding the study purpose, methodology, how to conduct administer self-administered questionnaire, how to take consent, keep confidentiality, and respect the right of the participants.

\section{Data quality control}

The quality of the data was assured by pretesting of questionnaire on $5 \%$ of the sample (9 Nurses) in Bahirdar Felegehiwot Hospital prior to the start of the actual study to test the fitness of the questionnaire for the study settings, Based on the result of the pretest, some ambiguous questionnaire will modified for clarity and consistency. Training about the data collection tool as well as data collection procedures (ways of approaching the eligible Nurses and how to obtain 
permission for Self Administer Questionnaires) was given to data collectors and supervisors for a total of two days prior to the data collection process.

The objectives of the study were clearly explained to the data collectors as well as supervisors. The respondents were give brief orientation before they are given the Questionnaires and supervision will done at the spot by the supervisors. Throughout the course of the data collection, Data collectors were supervised at each site, regular meeting were held between the data collectors supervisor and the principal investigator to discuss the problem arising in each interview, and detailed feedback will provided to the data collectors.

In addition, the collected data was check daily for its completeness, accuracy, and clarity by supervisors. The reliability of the tool was determined based on the analysis result of the pretest which (Cronbach's alpha). The principal investigator checked every questionnaire before data entry. The Data will kept in the form of a file in a private secured place.

\section{Data processing and analysis}

After checking the completeness of the data, it was entered into Epi info version 7.2.0.1, and then; it will export to SPSS Version 24 for analysis. Descriptive analysis was done by computing proportions and summary statistics. The association between each independent variable and the outcome variable was assessed by using binary logistic regression. All variables with $\mathrm{P} \leq 0.2$ in the bivariate analysis were included in the final model of multivariable analysis to control all possible confounders.

AOR along with 95\% CI were computed and $\mathrm{P}$ value $<0.05$ was considered to declare factors that have statistically significant association with the outcome by using multivariable analysis in the binary logistic regression. The goodness of fit was tested by Hosmer-Lemeshow statistic test. Finally; the result is presented in the form of texts, tables, and graphs.

\section{ETHICAL CONSIDERATION}

Ethical clearance was obtained from the Ethical Review Committee of Debre Tabor University, Research and Community service Directorate. Letter of permission will give to South Gondar zone health department and Debre Tabor town health office and each hospital. The patient data was assessed up on the approval of the medical director of each hospital. To ensure confidentiality, respondent identifier was not recorded in the data collection check list, and data was used only for the intended study. (for Detail sees Annexes-9.1) 


\section{Results}

\section{Socio-demographic and Economic characteristics of the study population}

According to the study, 95 (57.2\%) of the participants were Females and 71 (42.8\%) were males. The largest proportion, $69(41.6 \%)$ of the respondents were between the ages of 20 and 29 years and the smallest proportion, 29 (17.5\%) found between >=40 years. Majority of the respondents, 121(72.9\%) were first degree holders and 45 (27.1\%) of the respondents were diploma. Out of the total participants, $125(75.3 \%), 35(21.1 \%), 5(3 \%), 1(0.6 \%)$, were married, single, divorced and widowed marital status respectively. Regarding monthly income, 100 (60.2\%) were >=5000 monthly income, 63 (38.0\%) were 3001-4999 monthly income, 3 (1.8\%) were <3000 monthly income (Table 2).

\section{Workplace related characteristics of the study population}

Among study participants,64 (38.6\%),62 (37.3\%), and 40 (24.1\%) of the study participants had work experience in clinical area 5-10 years, less than 5 years ,and greater than 10 years respectively. Majority of study participants 142 (85.5\%) were Over worked status per day. In the Source of information on COVID19, the majority of participants headed from International health organization, e.g., WHO 103 (62\%) (Table 3).

\section{Knowledge about COVID-19 characteristics of study Population}

According to the study, $146(88.0 \%)$ respondents Knew C/M of COVID-19; majority of participants, 122 (73.5\%) Knew main C/M of COVID-19 were Fever and dry cough. Among the participants $138(83.1 \%)$ study participants knew the source of infection of COVID-19, and 142 (85.5\%) knew prevention methods of COVID-19. Majority of participants 152 (91.6\%) knee period of incubation for COVID-19, among which $123(74.1 \%)$ were response period of incubation for COVID-19 were 1 14 days. Majority of Study participants Response, 133 (80.1\%) Type of infectious Disease for COVID-19 was viral. . Regarding the Transmission route of COVID-19, majority, 165 (99.4\%) knew the Transmission route of COVID-19, among which 134 (80.7\%) were Respiratory droplets and close. In Susceptible to COVID-19, 96 (57.8\%) response People are generally susceptible, to The overall knowledge of nurses Knowledge Toward COVID-19 (knowledge of questions that were There currently is no effective cure for COVID-2019, but early symptomatic and supportive treatment can help most Patients recover from the infection, Not all persons with COVID-2019 will develop to severe 
cases. Only those who are elderly, have chronic illnesses, and are Obese are more likely to be severe cases, It is not necessary for children and young adults to take measures to prevent the infection by the COVID-19 virus, People who have contact with someone infected with the COVID-19 virus should be immediately isolated in a proper Place. In general, the observation period is 14 days, Eating or contacting wild animals would result in the infection by the COVID19 virus, Persons with COVID-2019 cannot transmit the virus to others when a fever is not Present, The COVID-19 virus spreads via respiratory droplets of infected individuals, Wearing general medical masks can prevent one from acquiring infection by the in COVID-19 virus, To prevent the infection by COVID-19, individuals should avoid going to crowded places such as bus parks and avoid taking public transportation, Isolation and treatment of people who are infected with the COVID-19 virus are effective ways to reduce the spread of the virus, The isolation period is 2 weeks for COVID-19, COVID-19 vaccine is available in markets, Antibiotics are the first-line treatment for COVID-19) were calculated based on $\leq 16$ by giving 0 for non-correct answers and 1 for correct answers of for all the 13 knowledge questions. Among respondents, $84.9 \%$ nurses had good knowledge, and the rests had poor knowledge on COVID19 (Table- 4).

\section{Attitude about COVID-19 characteristics of study Population}

Based on finding, 105(63.3\%) of respondents have favorable attitude for COVID-19 whereas the rest 61(36.7\%) have unfavorable attitude (Table 1).

\section{Factors associated with Knowledge of Nurses toward COVID-19}

Variables having p-value less than 0.2 during the biVariable analysis in the current study and variables considered as significant from other literatures were analyzed; and the multivariable analysis indicated that there was one variable that showed statistical significant with Knowledge of Nurses toward COVID-19 in south Gondar Hospitals . Wearing general medical masks can prevent one from acquiring infection by the co vid-19 virus $(\mathrm{AOR}=0.44,95 \% \mathrm{CI}=0.005-0.362$ were factors of knowledge about COVID-19 (Table-6).

\section{Factors associated with the Attitude of Nurses toward COVID-19}

Variables having p-value less than 0.2 during the bi Variable analysis in the current study and variables considered as significant from other literatures were analyzed; and the multivariable analysis indicated that there was one variable that showed statistical significant with the Attitude of Nurses toward COVID-19 in south Gondar Hospitals. Strongly agrees Medical staffs are 
ready to participate in antiepidemic in the community $(\mathrm{AOR}=0.08,95 \% \mathrm{CI}=(0.003-1.76$ were factors of attitude about COVID-19 (Table-7).

\section{DISCUSSION}

This study tried to address Knowledge, and Associated Factors toward COVID-19 among Nurses Who Work in South Gondar Zone Hospitals, Northwest Ethiopia 2020. The level of good Knowledge was found to be $84.9 \%$ (95\%CI: 77.8-90.4) among nurses towards COVID-19 in South Gondar Zone Hospitals. This result was higher as compared with other similar studies in Iran (56.5\%). And to address Attitude, and Associated Factors toward COVID-19 among Nurses Who Work in South Gondar Zone Hospitals, Northwest Ethiopia 2020. The level of favorable attitude was found to be $63.3 \%$ (95\%CI: 54.3-72.1) among nurses towards COVID-19 in South Gondar Zone, Hospitals. This result was lower as compared with other similar studies in China $(85 \%)$ feared self-infection with the virus,

This level of knowledge finding was in line with a study conducted study conducted in china from health care workers (89\%) (31). And in line with Japan Health care workers (89.5\%)(32). In line with a Study conducted in Egypt, level of knowledge among attitude HCWs( $80.4 \%$ ) (33). Study done in Ethiopia, 88.2\% of respondents had good knowledge (34). The similarity of this study with China, Japan, Egypt, and Ethiopia could be the study design and educational professional resemblance among health care workers.

However, the level of knowledge result of this study was much lower than the study done in Pakistan (93.2\%) (18). The possible explanation for the different could be study setting and individual health care provider's knowledge variability. The level of attitude results of this study was much lower than the study done in China (85\%)(31), in Japan (77.7\%), and Egypt 83.1\% (32) (33). In Study done in Ethiopia, 94.7\% of respondents had positive attitude (34). The possible justification for the different could be studies setting, individual health care provider's knowledge variability, and training taking regarding COVID-19.

This Result level of knowledge result was higher as compared with other similar studies such as research done at Iran nurses $(56.5 \%)(16)$. The possible justification for the difference could be the study period which is the study conducted in Iran was around near to occurrence of COVID19. In This study higher than with Study conducted in Amhara region, Ethiopia (70\%), HWs had good knowledge of COVID-19 (35). The possible justification for the different could be the target population. 
This level of Attitude result was higher as compared with other similar studies such as research done at Iran health care professionals $(21 \%)(20)$. The possible justification for the difference could be the study period which is the study conducted in Uganda was around near to occurrence of COVID-19.

In this study, in multivariable analysis, Wearing general medical masks can prevent one from acquiring infection by co vid-19 virus was remained significantly associated with the level of knowledge dependent variable with $95 \% \mathrm{CI}$ and $\mathrm{P}$ value of $\leq 0.05$.and in multivariable analysis Medical staffs are ready to participate in anti-epidemic in the community was remained significantly associated with the level of attitude dependent variable with at 95\% CI and Pvalue of $\leq 0.05$.

This study showed that Wearing general medical masks can prevent one from acquiring infection by co vid-19 virus $(\mathrm{AOR}=0.44,95 \% \mathrm{CI}=0.005-0.362$ were factors of knowledge about COVID-19. Whereas, strongly agree Medical staffs are ready to participate in antiepidemic in the community ( $\mathrm{AOR}=0.08,95 \% \mathrm{CI}=(0.003-1.76$ were factors of attitude about COVID- 19 . This finding was not supported by the other studies because there is no enough study conducted

\section{LIMITATION OF THE STUDY}

It was based on online data collection techniques using email and telegram. Some of the health workers might not have access to such services due to limited access to technology, internet service and electric power. Thus, they might not be sampled even if they are important to this study. Also, moreover, this study included nurses working only in government health facilities. Because it is a one-time study, it shared the limitations of a cross-sectional study to establish cause-effect relationships.

\section{CONCLUSION OF THE STUDY}

In this study, most of the nurses had good knowledge and favorable attitude regarding COVID19. Wearing general medical masks can prevent one from acquiring infection by co vid-19 virus were the factors in association with knowledge OF nurses on COVID-19. Similarly, Medical staffs are ready to participate in anti epidemic in the community factors association with attitudes of nurses on COVID-19.

\section{RECOMMENDATIONS}

\section{To health personnel/ HEWs}


Shall prevent his/her self from COVID-19.

\section{To Each Hospitals}

Providing Nurses, financial and administrational support is crucial.

* We recommend health education campaigns to the less educated nurses.

* Continuous provision of PPE and training of all nurses on proper infection prevention measures are serious and substantial.

\section{To the researchers}

* It is better if qualitative study is conducted.

\section{Abbreviation:}

AOR Adjusted Odds Ratio, CDC: Communicable Diseases Control; COVID-19: Coronavirus 2019, CI: Confidence Interval, FMOH: Federal Ministry of Health, HCWs: Health Care Workers, IP: Incubation Period, KA: Knowledge, Attitude, KAP: Knowledge, Attitude, Practice, $\mathrm{MOH}$ : Ministry of Health, $\mathrm{MOH}$ : Ministry of Health, PCR: Polymerase Chain Reaction, SPSS: Statistical Package for Social Sciences, WHO: World Health Organization

\section{Declarations}

Ethical approval and consent to participate: Ethical clearance was obtained from the Ethical Review Committee of Debre Tabor University, Research and Community service Directorate. Letter of permission will give to South Gondar zone health department and Debre Tabor town health office and each hospital. The patient data was assessed up on the approval of the medical director of each hospital. To ensure confidentiality, respondent identifier was not recorded in the data collection check list, and data was used only for the intended study.

Consent to publication: Not applicable

Availability of data and materials: Data will be available upon request from the corresponding author.

Competing interests: The authors declare that they have no competing interests.

Funding: This research did not receive any grant from any funding agency in the public, commercial, or not-for-profit sectors.

Authors' Contribution: DG, the corresponding author worked on designing the study, training and supervising the data collectors, interpreting the result, and preparing the manuscript. The co-authors, namely, SFS, ESC, played their role in analyzing and interpreting the result. 
Moreover, the co-authors wrote the manuscript. All authors were involved in reading and approving the final manuscript.

Acknowledgment: The author acknowledged co-authors, data collectors, and supervisors. The author is also deeply acknowledging Debretabour University. Finally, the respondents deserve sincere thanks for their kind of responses.

\section{REFERENCE}

1. FMOH,NATIONAL COMPREHENSIVE COVID19 MANAGEMENT HANDBOOK, Ethiopia First edition APRIL 2020.

2. The Novel Coronavirus Pneumonia Emergency Response Epidemiology Team. The epidemiological characteristics of an outbreak of 2019 novel coronavirus diseases (COVID-19) in China. Chin J Epidemiol. 2020; 41: 145-51.

3. Chen N, Zhou M, Dong X, Qu J, Gong F, Han Y, et al. Epidemiological and clinical characteristics of 99 cases of 2019 novel coronavirus pneumonia in Wuhan, China: a descriptive study. Lancet. 2020; 395: 507-13.

4. Mark Bradley, Coronavirus 2020: The Essential Guide for The Wuhan Virus (Symptoms, Transmission, and Prevention) Coronavirus Survival Guide,2020.

5. Eurosurveillance Editorial T. Note from the editors: World Health Organization declares novel coronavirus (2019-nCoV) sixth public health emergency of international concern. Euro surveillance : bulletin Europeen sur les maladies transmissibles = European communicable disease bulletin. 2020;25(5). Epub 2020/02/06.

6. World Health Organization. WHO announces COVID-19 outbreak a pandemic. http://www.euro.who.int/en/health-topics/health-emergencies/coronavirus-covid

19/news/news/2020/3/who-announces-covid-19-outbreak-a-pandemic [Accessed 12 March 2020].

7. Public Health Institute Public Health Emergency Management,COVID-19 Surveillance Situational Report-One.

8. Kharma MY, Alalwani MS, Amer MF, Tarakji B, Aws G. Assessment of the awareness level of dental students toward Middle East Respiratory Syndrome-coronavirus. J Int Soc Prev Community Dent. 2015;5(3):163-9. doi: 10.4103/2231-0762.159951. [PubMed: 26236674]. [PubMed Central: PMC4515797]. 
9. Zhou P, Yang XL, Wang XG, Hu B, Zhang L, Zhang W, et al. A pneumonia outbreak associated with a new coronavirus of probable bat origin. Nature. 2020;579(7798):270-3. doi: 10.1038/s41586-020-2012-7. [PubMed: 32015507]. [PubMed Central: PMC7095418].

10. Du Toit A. Outbreak of a novel coronavirus. Nat Rev Microbiol. 2020;18(3):123. doi: 10.1038/s41579-020-0332-0. [PubMed: 31988490]. [PubMed Central: PMC7073251].

11. Worldometers. COVID-19 coronavirus outbreak. 2020, [cited 2020 Mar 5]. Available from: https://www.worldometers.info/coronavirus/.

12. Jiang S, Shi Z, Shu Y, Song J, Gao GF, Tan W, et al. A distinct name is needed for the new coronavirus. Lancet. 2020;395(10228):949. doi: 10.1016/S0140-6736(20)30419-0. [PubMed: 32087125].

13. Lu H. Drug treatment options for the 2019-new coronavirus (2019-nCoV). Biosci Trends. 2020;14(1):69-71. doi: 10.5582/bst.2020.01020. [PubMed: 31996494].

14. Omrani AS, Shalhoub S. Middle East respiratory syndrome coronavirus (MERS-CoV): what lessons can we learn? J Hosp Infect. 2015;91(3):188-96. doi: 10.1016/j.jhin.2015.08.002. [PubMed: 26452615].

15. Coronovirus update,August 22th,2020.

16. Marzieh Nemati 1, Bahareh Ebrahimi 2, *, Fatemeh Nemati, Assessment of Iranian Nurses' Knowledge and Anxiety toward COVID-19 during the Current Outbreak in Iran,2020.

17. Amirhossein Erfani1, 2, Reza Shahriarirad1, 2,*, Keivan Ranjbar1, 2, Alireza Mirahmadizadeh3\& Mohsen Moghadami4, Knowledge, Attitude and Practice toward the Novel Coronavirus (COVID-19) Outbreak: A Population-Based Survey in Iran,2020.

18. Muhmmad Saqlain,1* Muhammad Muddasir Munir2, Saif ur Rehman3, Aqsa Gulzar4, Sahar Naz5, Zaheer Ahmed6, Azhar Hussain Tahir1, Muhammad Mashhood7, Knowledge, attitude, practice and perceived barriers among healthcare professionals regarding COVID-19: A Cross-sectional survey from Pakistan,2020.

19. Bao-Liang Zhong1,2,3, Wei Luo3, Hai-Mei Li2, Qian-Qian Zhang2, Xiao-Ge Liu3, Wen-Tian Li1,2,3*, Yi Li1,2,3*, Knowledge, attitudes, and practices towards COVID-19 among Chinese residents during the rapid rise period of the COVID-19 outbreak: a quick online crosssectional survey,2020; 16(10): 1745-1752. 
20. Ronald Olum1*†, Gaudencia Chekwech1, Godfrey Wekha1, Dianah Rhoda Nassozi 1 and Felix Bongomin2,3*†, Coronavirus Disease-2019: Knowledge, Attitude, and Practices of Health Care Workers at Makerere University Teaching Hospitals, Uganda,2020. .

21. Huynh Giao1,6*, Nguyen Thi Ngoc Han2, Tran Van Khanh3, Vo Kim Ngan4,5, Vo Van Tam1, Pham Le An6, Knowledge and attitude toward COVID-19 among healthcare workers at District 2 Hospital, Ho Chi Minh City,2020.

22. Ethiopian Public Health Institute Center of Public Health Emergency Management, Novel Corona Virus (2019-nCoV) Disease Factsheet,2020.

23. Federal ministry of Health ,Ethiopia,, Update Coronovirus reported on may10th ,2020.

24. FMOH, Ethiopia Confirms First Case of Coronavirus,2020.

25. World Health Organisation. Coronavirus Disease (COVID-19) Outbreak: Rights, Roles and Responsibilities of Health Workers, Including Key Considerations for Occupational Safety and Health. (2020). Available online at: www.who.int/publications-detail/coronavirus-disease(covid-19)-outbreak-rights-roles-and-responsibilities-of-health-workers-includingkeyconsiderations-for-occupational-safety-and-health (accessed April 05, 2020).

26. MedScape. In Memoriam: Healthcare Workers Who Have Died of COVID-19. (2020). Available online at: www.medscape.com/viewarticle/927976 (accessed April 06, 2020).

27. World Health Organisation. Emerging Respiratory Viruses, Including COVID19:Methods for Detection, Prevention, Response and Control. (2020). Available online at: www.openwho.org/courses/introduction-to-ncov (accessed March18, 2020).

28. Ajilore K, Atakiti I, Onyenankey K. College students' knowledge, attitudes and adherence to public service announcements on Ebola in Nigeria: Suggestions for improving future Ebola prevention education programmes. Health Education Journal. 2017; 76: 648-60.

29. Tachfouti N, Slama K, Berraho M, Nejjari C. The impact of knowledge and attitudes on adherence to tuberculosis treatment: a case-control study in a Moroccan region. Pan Afr Med J. 2012; $12: 52$.

30. Fentahun A. South Gondar zone Health Department report, 2019: unpublished. 2019.

31. Minghe Zhou, Fang Tang, Yunjian Wang, Hanxiao Nie, Luyang Zhang, Guohua You, Min Zhang, Knowledge, attitude and practice regarding COVID-19 among health care workers in Henan, China,2020.32. Yudong Shi a,b,1, Juan Wang a,b,1, Yating Yang a,b,1, Zhiqiang Wang c, Guoqing Wang c, Kenji Hashimoto d, Kai Zhang a,b,*, Huanzhong Liu a,b,**, 
Knowledge and attitudes of medical staff in Chinese psychiatric hospitals regarding COVID$19,2020$.

33. Wafaa Yousif Abdel Wahed1 - Enas Mamdouh Hefzy2 • Mona Ibrahim Ahmed3 . Nashwa Sayed Hamed1, Assessment of Knowledge, Attitudes, and Perception of Health Care Workers Regarding COVID-19, A Cross-Sectional Study from Egypt.

34. Bedru J. e tal. Knowledge, attitude and practice of healthcare workers towards COVID19 and its prevention in Ethiopia: a multicenter study,2020.

35. Mulusew Andualem Asemahagn, Factors determining the knowledge and prevention practice of healthcare workers towards COVID-19 in Amhara region, Ethiopia: a cross-sectional survey, Tropical Medicine and Health (2020) 48:72. 


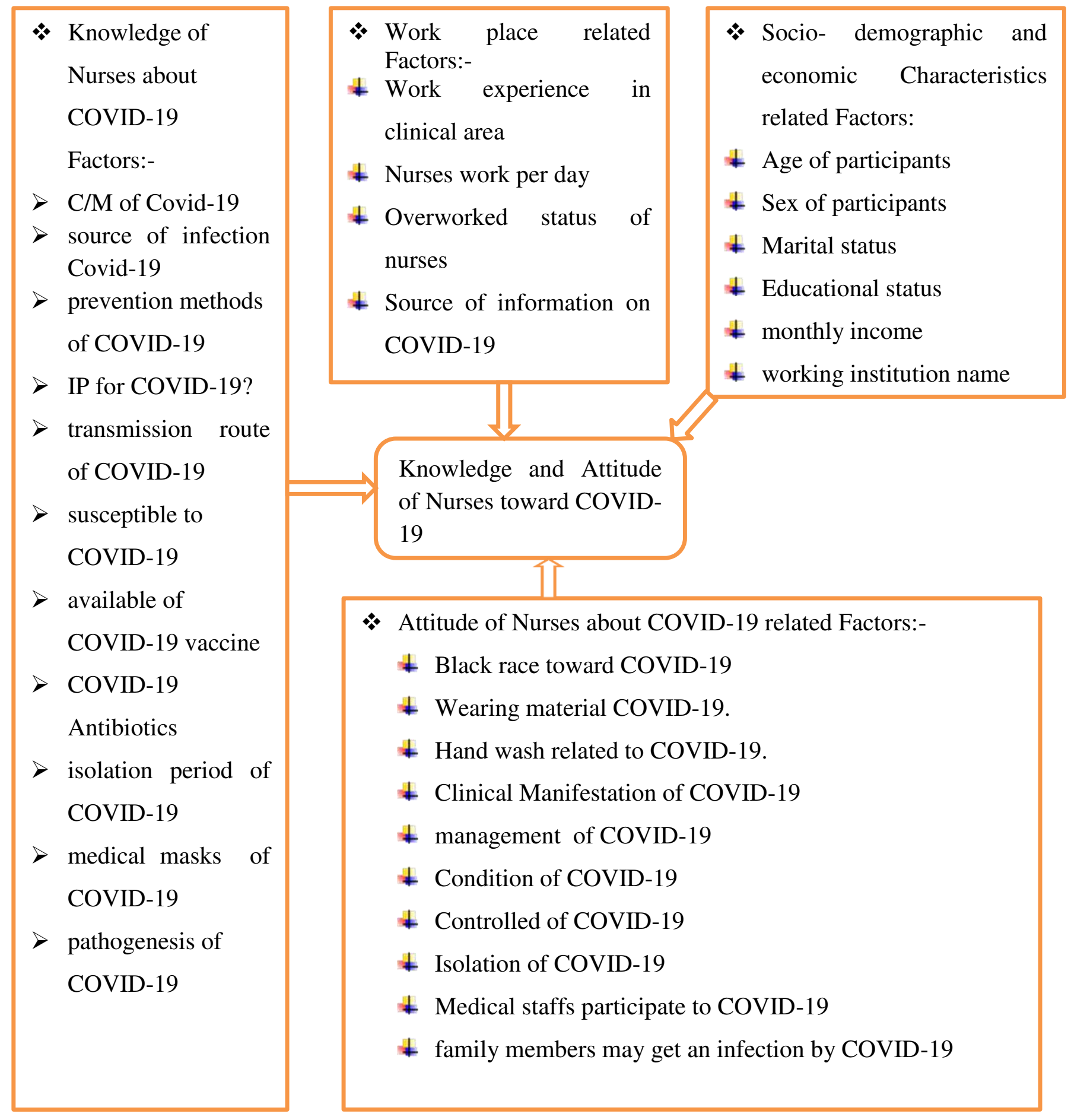

Figure 2: Conceptual framework of Assessment of Knowledge, Attitude and Associated Factors toward COVID-19 among Nurses Who Works in South Gondar Zone, Hospitals, and Northwest Ethiopia 2020. (Adapted from different articles (16-21, 31)) 


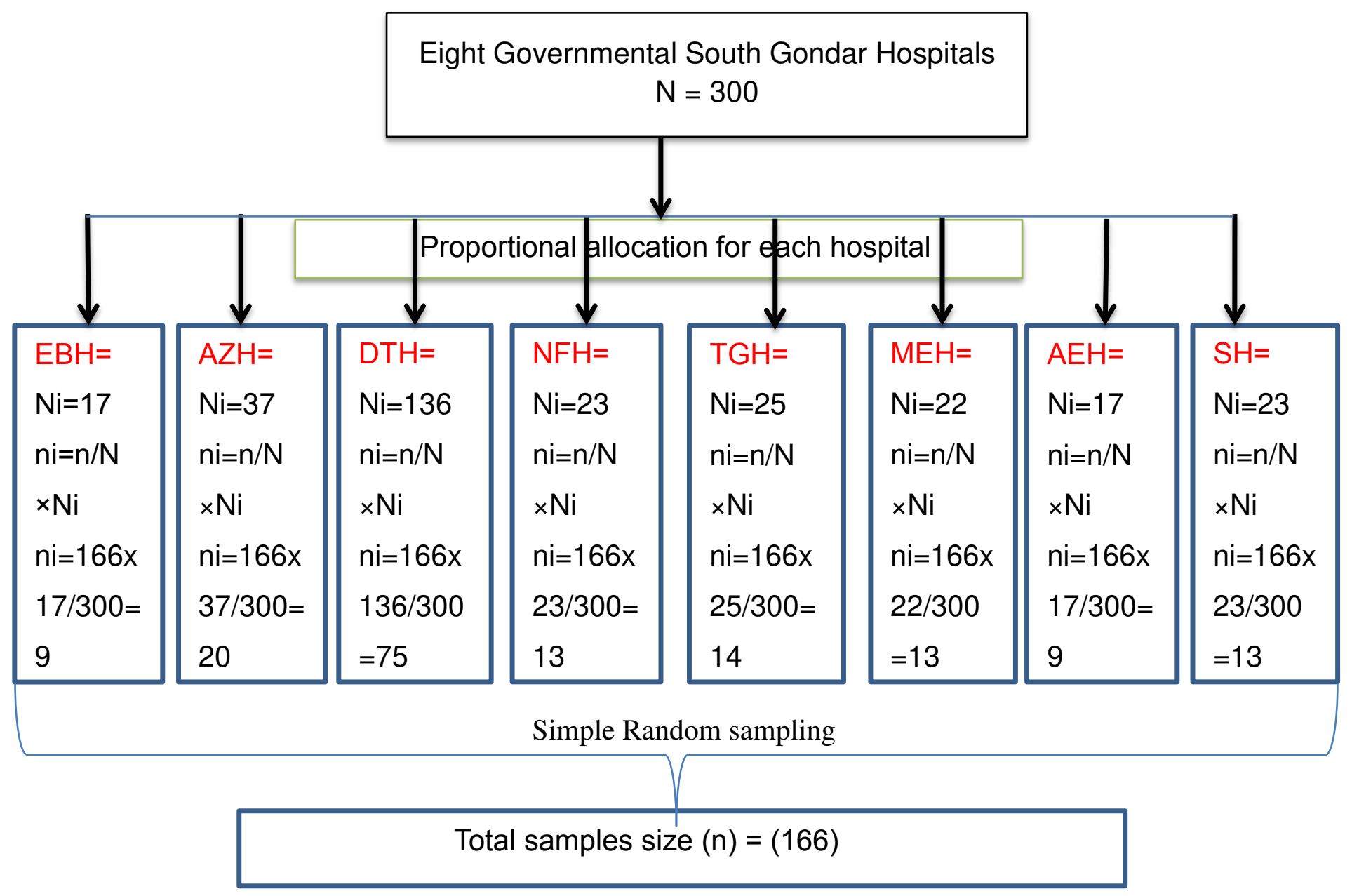

Figure 3:-Schematic Presentation of the Sampling Procedure for Knowledge, Attitude and Associated Factors toward COVID-19 among Nurses Who Works in South Gondar Zone, Hospitals, and Northwest Ethiopia 2020.

Key:

EBH: Ebnat Hospital, AZH: Adiss Zemen Hospital, DTH; Debre Tabor Hospital, NFH: Nifas Mewucha Hospital, TGH:Tach Gayint Hospital, MEH: Mekan Eyesus Hospital, AEH: Andabet Etie Hospital, SH: Simada Hospital, N: Total number of Nurses in the South Gondar Hospitals $\mathrm{Ni}$ : total number of Nurses in each selected Hospitals, ni=: proportion of Nurses in each selected Hospitals, n: Total sample size 
Table 2: Socio-demographic and Economic characteristics of study participants in South Gondar Zone, Hospitals, Northwest Ethiopia $(\mathrm{N}=166)$.

Variable

category

Frequency Percent

Name of Hospitals Nurses works

Debre Tabor General Hospital

75

(\%)

Ebinat District Hospital

9

$45.2 \%$

Adiss Zemen District Hospital

20

$5.4 \%$

Nifas Mewucha District Hospital

$12 \%$

Tach Gayint District Hospital

13

$7.8 \%$

Simada District Hospital

14

$8.4 \%$

Mekane Eyesus District Hospital

Andabet District Hospital

$7.8 \%$

Male

13

$5.4 \%$

Sex

Female

71

$42.8 \%$

20-29

95

$57.2 \%$

Age

30-39

69

$41.6 \%$

$>=40$

68

$41 \%$

Marital Status

Single

17.5

Married

35

$21.1 \%$

Widowed

Divorced

125

$75.3 \%$

Diploma

$0.6 \%$

$1^{\text {st }}$ Degree

1

5

45

121

$<3000$

30001-4999

3

63

$3 \%$

$>=5000$

100

$27.1 \%$

$72.9 \%$

$1.8 \%$

$38 \%$

60.2

\section{Sales}

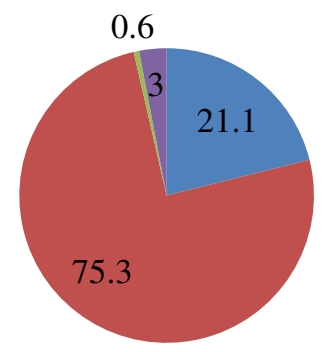

- Single

- Married

- Widowed

- Divorced

Figure 4: -Distribution of marital status of study participants in in South Gondar Zone, Hospitals, Northwest Ethiopia $(\mathrm{N}=166)$. 
Table 3: Work place related characteristics of study participants in South Gondar Zone, Hospitals, Northwest Ethiopia ( $\mathrm{N}=166)$.

Variable category Frequency Percent

Work experience in clinical area

$<5$ years

62

$37.3 \%$

$5-10$ years

64 $38.6 \%$

$>=10$ years

40

$<=8$ hours

24

$24.1 \%$

Nurses Over worked status per day

$>8$ hours

142

$14.5 \%$

International health organization e.g., WHO

103

$85.5 \%$

Source of information on COVID19

Government sites and media e.g., $\mathrm{MOH}$ of Ethiopia 86 $62 \%$

Social media e.g., Whats App, Facebook 75

News media e.g., TV, radio, newspaper

64

$51.8 \%$

Journals

18

$45.2 \%$

Others

1

$38.6 \%$ $10.8 \%$

$0.6 \%$

Table 4: Work place related characteristics of study participants in South Gondar Zone, Hospitals, Northwest Ethiopia ( $\mathrm{N}=166)$.

Variable

Knew C/M of COVID-19

Knew main C/M of COVID-19

Knew source of infection COVID-19

a source of infection COVID-19 category

yes

no

Fever and dry cough.

Fatigue

Stuffy and runny nose

Sore throat and myalgia.

Diarrhea

I don't know.

yes

no

Anyone residing in or travelled to affected areas, contacts / travelling with someone having symptoms of severe acute respiratory infection.

the air by coughing and 90
Frequency Percent

(\%)

146

20

122

4

15

15

4

1

138

28

89

$88.0 \%$

$12.0 \%$

$73.5 \%$

$2.4 \%$

$9.0 \%$

$9.0 \%$

$2.4 \%$

$0.6 \%$

$83.1 \%$ $16.9 \%$

$53.6 \%$

$54.2 \%$ 
prevention methods of COVID-19

a prevention method of COVID-19
Knew period of incubation for COVID-19

Knew period of incubation for COVID-19

Knew Type of infectious

Disease is COVID-19

Knew Transmission route of COVID-19

The main transmission route of COVID-19

Susceptible to

COVID-19 sneezing, close personal contact such as touching and shaking hands, touching contaminated object or surfaces,

touching mouth, nose, eyes before washing hands rarely fecal contamination $\quad 28$

yes

no

Maintaining basic hand and 113 respiratory hygiene (include regular hand washing, covering mouth and nose when coughing and sneezing)

Safe food practices, thoroughly 53 cooking meat and eggs

Avoiding close contact with 65 anyone showing symptoms of respiratory illness such as coughing and sneezing

Avoiding close contact with 51 live or dead farm or wild animals

yes

no

$1 \sim 14$ days

$3 \sim 7$ days.

More than 14 days

21

I don't know

1

Bacterial 28

Viral

133

I don't know.

5

yes

no 1

Respiratory droplets and close

134

Water. 20

Food.

5

I don't know

4

The old and children

People are generally 96 susceptible

Young adults

4

People with pre-existing 22 diseases
$31.9 \%$

$24.7 \%$

$16.9 \%$ $85.5 \%$ $14.5 \%$ $68.1 \%$

$39.2 \%$

$30.7 \%$

$91.6 \%$ $8.4 \%$

$74.1 \%$ $3.0 \%$ $12.7 \%$ $0.6 \%$ $16.9 \%$ $80.1 \%$ $3.0 \%$ $99.4 \%$ $0.6 \%$ $80.7 \%$ $12.0 \%$ $3.0 \%$ $2.4 \%$ $24.7 \%$ $57.8 \%$ $2.4 \%$ $13.3 \%$ 
There currently is no effective cure for COVID-2019, but True

early symptomatic and supportive treatment can help most

Patients recover from the infection

People who have contact with someone infected with the COVID-19 virus should be immediately isolated in a proper Place. In general, the observation period is 14 days.
I don't know.

False

True

False

I don't know.

True

False

I don't know.

True

False
Persons with COVID-2019 cannot transmit the virus to True

False

False

I don't know.

Wearing general medical masks can prevent one from True False acquiring infection by theCOVID-19 virus. $\begin{array}{ll}\text { To prevent the infection by COVID-19, individuals should } & \text { True } \\ \text { avoid going to crowded places such as bus parks and avoid } & \text { False }\end{array}$ taking public transportations Isolation and treatment of people who are infected with the True COVID-19 virus are effective ways to reduce the spread of the virus.

False

I don't know.

Yes

no

Yes

no

Yes

no
$5.4 \%$

$44.6 \%$

$55.4 \%$

$71.7 \%$

$27.1 \%$

2

102

64

127

39

$1.2 \%$

$61.4 \%$

$38.6 \%$

$76.5 \%$

$23.5 \%$

125

$75.3 \%$

38

$22.9 \%$

3

125

$1.8 \%$

$75.3 \%$

41

37

129

40

126
$24.7 \%$

$22.3 \%$

$77.7 \%$

$24.1 \%$ $75.9 \%$ 
Table 5: Attitude of nurses working in South Gondar Zone, Hospitals, Northwest Ethiopia $(\mathrm{N}=166)$.

Characters

S.Disagree Disagree Neutral Agree $\quad$ S. agree
disease.

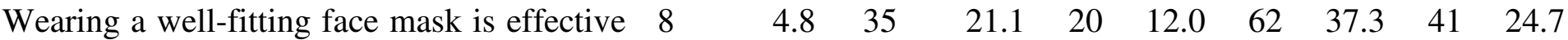
in preventing COVID-19.

$\begin{array}{lllllllllll}\text { Using a hand wash can prevent you from } 3 & 1.8 & 19 & 11.4 & 14 & 8.4 & 83 & 50.0 & 47 & 28.3\end{array}$ getting COVID-19.

When a patient has signs and symptoms of $11 \quad \begin{array}{llllllllll}0.6 & 29 & 17.5 & 34 & 20.5 & 75 & 45.2 & 27 & 16.3\end{array}$ COVID-19, I can confidently

$\begin{array}{llllllllllll}\text { Participate in the management of the patient. } & 6 & 3.6 & 14 & 8.4 & 32 & 19.3 & 75 & 45.2 & 39 & 23.5\end{array}$

Ethiopia is in a good position to contain $14 \quad \begin{array}{lllllllll}8.4 & 28 & 16.9 & 26 & 15.7 & 70 & 42.2 & 28 & 16.9\end{array}$

COVID-19

COVID-19 will finally be successfully $46 \quad \begin{array}{llllllllll} & 46 & 16 & 9.6 & 27 & 16.3 & 40 & 24.1 & 37 & 22.3\end{array}$ controlled? 7

Covid-19 patients should be kept in isolation $\quad \begin{array}{lllllllllll}10 & 6.0 & 22 & 13.3 & 20 & 12.0 & 63 & 38.0 & 51 & 30.7\end{array}$

Medical staffs are ready to participate in $4 \quad \begin{array}{lllllllll}2.4 & 8 & 4.8 & 28 & 16.9 & 74 & 44.6 & 52 & 31.3\end{array}$ anti-epidemic in the community

You are worried one of your family members $\quad \begin{array}{lllllllllll}3 & 3.0 & 14 & 8.4 & 8 & 4.8 & 82 & 49.4 & 57 & 34.3\end{array}$ may get an infection

Table 6: Factors associated with Knowledge of Nurses toward COVID-19 in South Gondar Zone Hospitals, Northwest Ethiopia, 2020.

Variable

There currently is no effective cure for COVID-2019, but early symptomatic and supportive treatment can help most

Patients recover from the infection

It is not necessary for children and young adults to take measures to prevent the infection by the COVID-19 virus

Wearing general medical mask can prevent one from acquiring infection by theCOVID-19 virus. category Knowledge of Nurses COR(95\% CI) toward COVID-19 good poor

True $\quad 104(0.8) \quad 24(0.2) \quad .117(.015-.896)$

$\begin{array}{llll}\text { False } & 1(0.03) & 37(0.97) & 1\end{array}$
$\operatorname{AOR}(95 \% \mathrm{CI}) \quad \mathrm{pv}$

$\mathrm{pv}$ $\begin{array}{llll}\text { True } & 62(0.76) & 20(0.24) & .196(.007-.552)\end{array}$

$\begin{array}{lll}\text { False } & 79(0.94) \quad 5(0.06) & 1\end{array}$ 
COVID-19 vaccine is available no in markets

Antibiotics are the first-line no treatment for COVID-19?
$117(0.9) \quad 12(0.1) \quad 5.28(2.12-12.98)$

24(0.65) $\quad 13(0.35) \quad 1$

$117(0.93) \quad 9(0.07) \quad 8.66(3.42-21.91)$

yes $\quad 24(0.6) \quad 16(0.4) \quad 1$

Table 7: Factors associated with Attitude of Nurses toward COVID-19 in South Gondar Zone Hospitals, Northwest Ethiopia, 2020.

\begin{tabular}{|c|c|c|c|c|c|c|}
\hline \multirow[t]{2}{*}{ Variable } & \multirow[t]{2}{*}{ category } & \multicolumn{2}{|c|}{$\begin{array}{l}\text { Attitude of Nurses } \\
\text { toward COVID-19 }\end{array}$} & \multirow[t]{2}{*}{$\mathrm{COR}(95 \% \mathrm{CI})$} & \multirow[t]{2}{*}{$\begin{array}{l}\text { AOR } \\
(95 \% \mathrm{CI})\end{array}$} & \multirow[t]{2}{*}{$\mathrm{pv}$} \\
\hline & & favorable & $\begin{array}{l}\text { Un } \\
\text { favorable }\end{array}$ & & & \\
\hline \multirow{2}{*}{$\begin{array}{l}\text { Did you know prevention methods of } \\
\text { COVID-19 }\end{array}$} & yes & $84(0.6)$ & $58(0.4)$ & $0.21(0.59-0.72)$ & & \\
\hline & no & $21(0.88)$ & $3(0.12)$ & 1 & & \\
\hline \multirow{2}{*}{$\begin{array}{l}\text { What type of infectious } \\
\text { Disease is COVID-19? }\end{array}$} & Viral & $77(0.58)$ & $56(0.42)$ & $0.25(0.09-0.68)$ & & \\
\hline & $\begin{array}{l}\text { Bacteria } \\
1\end{array}$ & $28(0.85)$ & $5(0.15)$ & 1 & & \\
\hline \multirow{2}{*}{$\begin{array}{l}\text { There currently is no effective cure for } \\
\text { COVID-2019, but early symptomatic and } \\
\text { supportive treatment can help most Patients } \\
\text { recover from the infection }\end{array}$} & True & $73(0.57)$ & $55(0.43)$ & $\begin{array}{l}0.052(.0 .07- \\
0.392)\end{array}$ & & \\
\hline & False & $32(0.84)$ & $6(0.16)$ & 1 & & \\
\hline \multirow{2}{*}{$\begin{array}{l}\text { Not all persons with COVID-2019 will } \\
\text { develop to severe cases. Only those who are } \\
\text { elderly, have chronic illnesses, and are Obese } \\
\text { are more likely to be severe cases. }\end{array}$} & True & $60(0.63)$ & $54(0.47)$ & $0.17(0.07-0.47)$ & & \\
\hline & False & $45(0.87)$ & $7(0.13)$ & 1 & & \\
\hline \multirow{2}{*}{$\begin{array}{l}\text { Persons with COVID-2019 cannot transmit } \\
\text { the virus to others when a fever is not } \\
\text { Present. }\end{array}$} & false & $54(0.73)$ & $20(0.27)$ & $0.46(0.24-0.89)$ & & \\
\hline & true & $51(0.55)$ & $41(0.44)$ & 1 & & \\
\hline \multirow{2}{*}{$\begin{array}{l}\text { Wearing general medical masks can prevent } \\
\text { one from acquiring infection by the COVID- } \\
19 \text { virus. }\end{array}$} & true & $57(0.56)$ & $45(0.44)$ & $0.42(0.21-0.84)$ & & \\
\hline & \begin{tabular}{|l|} 
false \\
\end{tabular} & $48(0.75)$ & $16(0.25)$ & 1 & & \\
\hline \multirow[t]{2}{*}{ COVID-19 vaccine is available in markets } & no & $80(0.62)$ & $49(0.38)$ & $0.78(0.36-1.70)$ & & \\
\hline & yes & $25(0.68)$ & $12(0.32)$ & 1 & & \\
\hline
\end{tabular}




\begin{tabular}{|c|c|c|c|c|c|c|}
\hline \multirow{2}{*}{$\begin{array}{l}\text { Antibiotics are the first-line treatment for } \\
\text { COVID-19? }\end{array}$} & no & $77(0.61)$ & 49(0.39) & $0.67(0.31-1.45)$ & & \\
\hline & yes & $28(0.70)$ & $12(0.3)$ & 1 & & \\
\hline \multirow[t]{5}{*}{$\begin{array}{l}\text { Medical staffs are ready to participate in } \\
\text { anti-epidemic in the community }\end{array}$} & S.agree & $46(0.88)$ & $6(0.12)$ & $0.33(0.27-4.19)$ & $\begin{array}{l}0.08(0.003 \\
-1.76)\end{array}$ & $\begin{array}{l}0.1 \\
1\end{array}$ \\
\hline & agree & $42(0.57)$ & $32(0.43)$ & $0.87(0.11-7.05)$ & $\begin{array}{l}0.01(0.00- \\
0.54)\end{array}$ & $\begin{array}{l}0.0 \\
0\end{array}$ \\
\hline & Neutral & $13(0.46)$ & $28(0.54)$ & $1.31(0.18-9.83)$ & $\begin{array}{l}0.46(0.01- \\
0.21)\end{array}$ & $\begin{array}{l}0.0 \\
0\end{array}$ \\
\hline & D.agree & $2(0.25)$ & $6(0.75)$ & 7.67(0.91-64.9) & $\begin{array}{l}0.09(0.28- \\
0.31)\end{array}$ & $\begin{array}{l}0.0 \\
0\end{array}$ \\
\hline & $\begin{array}{l}\text { SD. } \\
\text { agree }\end{array}$ & $2(0.5)$ & $2(0.5)$ & 1 & 1 & \\
\hline
\end{tabular}


Figures

Figure 1 was omitted by the authors in this version of the paper.

Figure 1

This image was omitted in this version of the submission 


\begin{tabular}{|c|c|c|}
\hline $\begin{aligned} & \text { Knowledge of } \\
& \text { Nurses about } \\
& \text { COVID-19 } \text { Factors:- } \\
&> \text { C/M of Covid-19 } \\
&> \text { source of infection } \\
& \text { Covid-19 } \\
&> \text { prevention methods } \\
& \text { of COVID-19 } \\
&> \text { IP for COVID-19? } \\
&> \text { transmission route } \\
& \text { of COVID-19 } \\
&> \text { susceptible to } \\
& \text { COVID-19 } \\
&> \text { available of } \\
& \text { COVID-19 vaccine } \\
&> \text { COVID-19 } \\
& \text { Antibiotics } \\
&> \text { isolation period of } \\
& \text { COVID-19 } \text { medical masks of } \\
& \text { COVID-19 } \\
& \text { pathogenesis of } \\
& \text { COVID-19 }\end{aligned}$ & 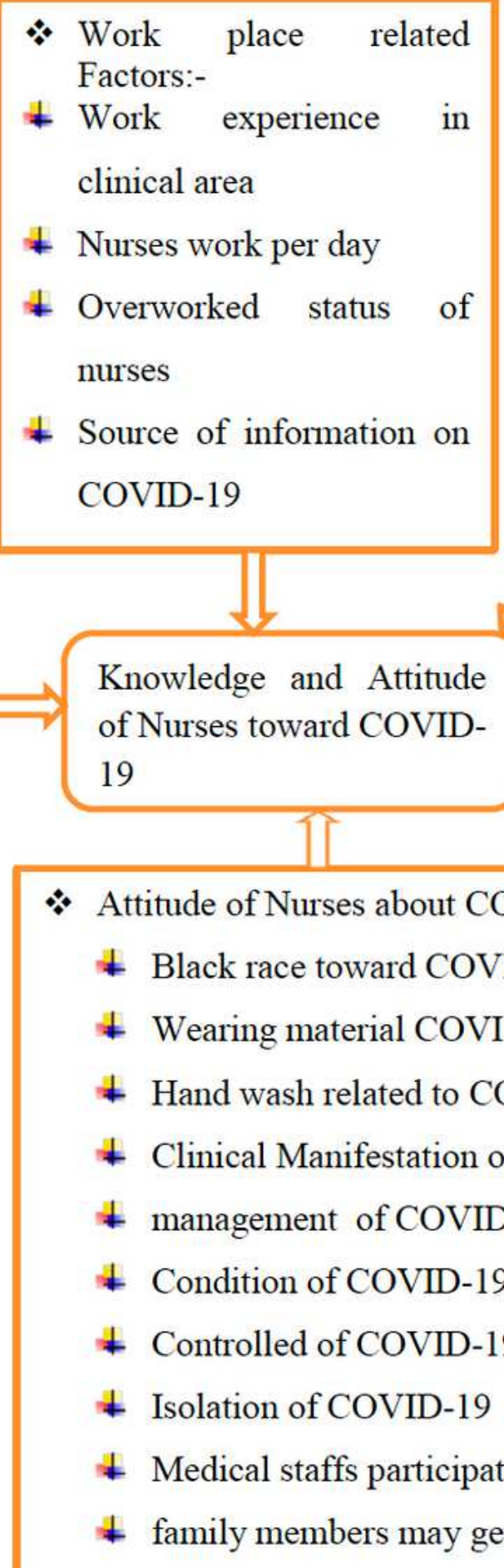 & $\begin{array}{l}\text { * Socio- demographic and } \\
\text { economic Characteristics } \\
\text { related Factors: } \\
\text { * Age of participants } \\
\text { * Sex of participants } \\
\text { * Marital status } \\
\text { * Educational status } \\
\text { * monthly income } \\
\text { * } \text { working institution name }\end{array}$ \\
\hline
\end{tabular}

\section{Figure 2}

Conceptual framework of Assessment of Knowledge, Attitude and Associated Factors toward COVID-19 among Nurses Who Works in South Gondar Zone, Hospitals, and Northwest Ethiopia 2020. (Adapted from different articles $(16-21,31))$ 


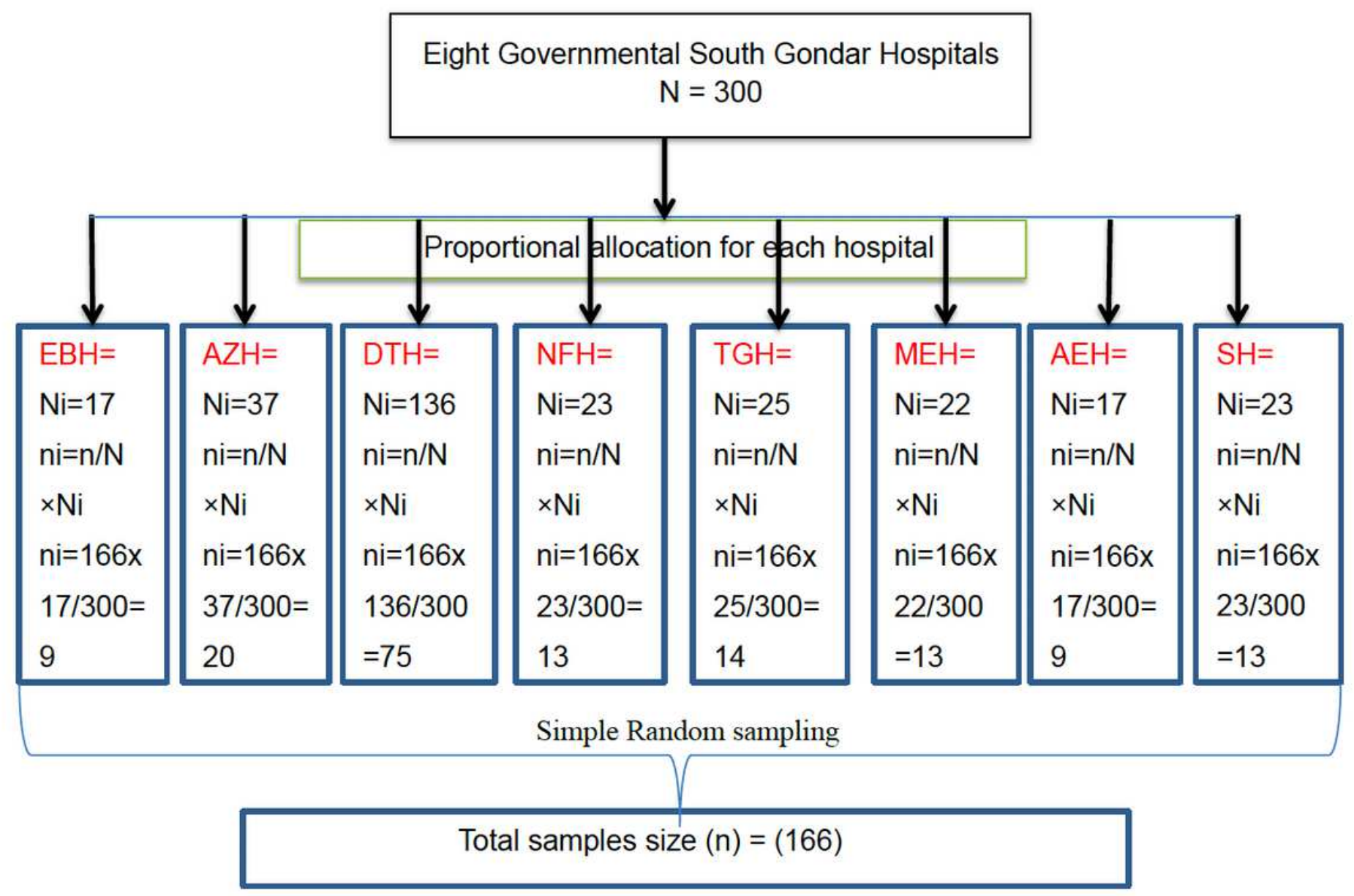

Figure 3

Schematic Presentation of the Sampling Procedure for Knowledge, Attitude and Associated Factors toward COVID-19 among Nurses Who Works in South Gondar Zone, Hospitals, and Northwest Ethiopia 2020. Key: EBH: Ebnat Hospital, AZH: Adiss Zemen Hospital, DTH; Debre Tabor Hospital, NFH: Nifas Mewucha Hospital, TGH:Tach Gayint Hospital, MEH: Mekan Eyesus Hospital, AEH: Andabet Etie Hospital, SH: Simada Hospital, N: Total number of Nurses in the South Gondar Hospitals Ni: total number of Nurses in each selected Hospitals, ni=: proportion of Nurses in each selected Hospitals, $\mathrm{n}$ : Total sample size 


\section{Sales}

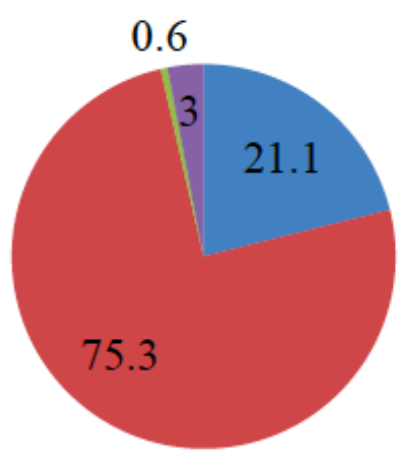

- Single

- Married

Widowed

- Divorced

\section{Figure 4}

Distribution of marital status of study participants in in South Gondar Zone, Hospitals, Northwest Ethiopia ( $\mathrm{N}=166)$. 